J. Dairy Sci. 97:5017-5022

http://dx.doi.org/10.3168/jds.2014-8036

(C) American Dairy Science Association ${ }^{\circledR}, 2014$. Open access under CC BY-NC-ND license.

\title{
Technical note: A noninvasive method for measuring mammary apoptosis and epithelial cell activation in dairy animals using microparticles extracted from milk
}

\author{
G. E. Pollott, ${ }^{* 1}$ K. Wilson, $†$ L. Jerram, $†$ R. C. Fowkes, $†$ and C. Lawson† \\ *Department of Production and Public Health, and \\ †Department of Comparative Biosciences, Royal Veterinary College, Royal College Street, London, NW1 0TU, UK
}

\begin{abstract}
Milk production from dairy animals has been described in terms of 3 processes: the increase in secretory cell numbers in late pregnancy and early lactation, secretion rate of milk per cell, and the decline in cell numbers as lactation progresses. This latter process is thought to be determined by the level of programmed cell death (apoptosis) found in the animal. Until now, apoptosis has been measured by taking udder biopsies, using magnetic resonance imaging scans, or using animals postmortem. This paper describes an alternative, noninvasive method for estimating apoptosis by measuring microparticles in milk samples. Microparticles are the product of several processes in dairy animals, including apoptosis. Milk samples from 12 Holstein cows, at or past peak lactation, were collected at 5 monthly samplings. The samples $(\mathrm{n}=57)$ were used to measure the number of microparticles and calculate microparticle density for 4 metrics: annexin $\mathrm{V}$ positive and merocyanine 540 dye positive, for both and total particles, in both whole milk (WM) and spun milk. Various measures of milk production were also recorded for the 12 cows, including daily milk yield, fat and protein percentage in the milk, somatic cell count, and the days in milk when the samples were taken. A high correlation was found between the $4 \mathrm{WM}$ microparticle densities and days in milk (0.46 to 0.64 ), and a moderate correlation between WM microparticle densities and daily milk yield $(-0.33$ to -0.44$)$. No significant relationships were found involving spun milk samples, somatic cell count, or fat and protein percentage. General linear model analyses revealed differences between cows for both level of microparticle density and its rate of change in late lactation. Persistency of lactation was also found to be correlated with the WM microparticle traits $(-0.65$ to -0.32$)$. As apoptosis is likely to be the major contributor to microparticle numbers in
\end{abstract}

Received February 10, 2014.

Accepted April 30, 2014.

${ }^{1}$ Corresponding author: gpollott@rvc.ac.uk late lactation, this work found a noninvasive method for estimating apoptosis that gave promising results. Further investigation is required to find out the factors affecting microparticle production and how it changes throughout lactation.

Key words: apoptosis, lactation, microparticle, persistency

\section{Technical Note}

Dairy cows produce milk with a very characteristic pattern of a sharp yield increase in early lactation and a slower decline in later lactation. An exploration of the underlying biological basis of lactation as a way of describing the lactation curve of dairy animals has proposed 3 key processes (Pollott, 2000). These are secretion rate per active mammary cell, the rate of cell proliferation in early lactation, and the rate of cell death in late lactation. This decline in later lactation has been attributed to a net loss of active secretory cells rather than a decline in cell activity (Knight and Wilde, 1993; Knight et al., 1998; Capuco et al., 2003). Attempts to measure the underlying cause of this decline in milk yield have been somewhat problematic, with Knight et al. (1998) reporting the use of laddered DNA as a sign of mammary cell apoptosis (programmed cell death). Their approach required the collection of mammary tissue samples by slaughter or mammary biopsy. Capuco et al. (2001) came to similar conclusions using DNA collected from the whole udders of nonpregnant lactating cows slaughtered at 4 time points during lactation. In the current study, we took a noninvasive approach through the measurement of microparticles collected from milk, which may be indicative of apoptosis.

If the 3 components of milk yield can be definitively measured, then a better understanding of factors affecting lactation yield, length, and persistency can be developed. Knight et al. (1998) suggested that within any given milking regimen the secretion rate per cell remains constant throughout lactation. Assuming this is the case, then the number of secretory cells in the udder becomes even more important in determining 
productivity and persistence of lactation. Studies by Capuco et al. (2001) and Stefanon et al. (2002) suggested that following peak lactation, the decline in milk yield as lactation progresses is strongly influenced by the rate of apoptosis. Through biopsy, DNA measurement, and magnetic resonance imaging (MRI) of caprine mammary parenchyma it was found that differentiation and proliferation of mammary secretory tissue occurs during late gestation and the first few weeks of lactation (Knight and Peaker, 1984; Knight and Wilde, 1993). Similar studies have also shown decreases in the amount of DNA detected between peak lactation and drying off, suggestive of decreasing numbers of secretory cells, as DNA quantity is related to the number of cells (Wilde et al., 1997; Capuco et al., 2001). Knight and Wilde (1993) and Quarrie et al. (1995) used DNA laddering to identify cell death, whereas Capuco et al. (2001) used terminal deoxyuridine triphosphate nickend labeling to estimate apoptosis. However, the factors involved in determining the rate of apoptosis are poorly understood, although it may be that minimizing the stimuli for apoptosis can lead to improved persistence and better lactation yields (Stefanon et al., 2002). Studies have suggested that numerous factors, both management related and physiological, influence the persistency of lactation (Stefanon et al., 2002; Capuco et al., 2003; Yart et al., 2012). Previously, it has been difficult to quantify the rate of apoptosis in the live animal, resulting in many lactation models being based on mathematical analysis of lactation records (Pollott, 2004; Albarrán-Portillo and Pollott, 2008).

Microparticles are membrane-bound vesicles of less than 1- $\mu \mathrm{m}$ diameter released from many different cell types, including erythrocytes, leucocytes, platelets, and endothelial cells (Nantakomol et al., 2008), and, importantly for this study, cells of epithelioid origin (Burnett et al., 2012). They are released, most commonly, at times of cell activation and apoptosis (Azevedo, 2012). Microparticles are formed by blebbing of the parent cell membrane (Orozco and Lewis, 2010), causing a loss of phospholipid asymmetry. Phosphatidylserine and phosphatidylethanolamine are negatively charged phospholipids found on the inner leaflet of the plasma membrane in healthy cells. During cell membrane blebbing and microparticle formation these phospholipids become exposed on the outer leaflet of the plasma membrane and the outer surface of the microparticle (Diamant et al., 2004). It is the presence of these normally hidden molecules that allow for the detection of microparticles. The phosphatidylserine specifically binds to annexin V, a calcium-dependent phospholipid-binding protein, and has been used to quantify microparticles in numerous studies (Théry et al., 2009; Azevedo, 2012; van der Pol et al., 2012), whereas the negatively charged lipophilic dye merocyanine (MC) 540 has also been used to detect the presence of disordered phospholipids on the membranes of microparticles (McCarthy et al., 2008). In addition to this, the outer membrane of the microparticle also contains membrane receptors and proteins originating from the parent cell, which can be detected using specific fluorochrome-labeled antibodies (Nantakomol et al., 2008; Azevedo, 2012). As microparticle formation could be the result of apoptosis (Diamant et al., 2004; Azevedo, 2012) and can be quantitatively measured (Nantakomol et al., 2008; Orozco and Lewis, 2010), we hypothesized that if microparticles can be detected in milk, then they may be able to give a quantitative value to the rate of apoptosis in the udder as lactation progresses.

The aim of this study was to identify the presence of microparticles in bovine milk and assess how their numbers changed with respect to stage of lactation and other factors, including milk production, indicators of mastitis, and protein and fat content of milk.

\section{Sample Collection}

All animals used in this study were part of the commercial dairy herd of the Royal Veterinary College (London, UK) and were not subjected to any extra experimental procedures over and above the normal day-to-day practices of such a herd and milk sampling during milking. Milk samples were taken from Holstein cows at, or after, peak lactation to follow the subsequent decline in yield. Samples were taken within a few days of the routine monthly milk sampling operated by National Milk Records Ltd. (Harrogate, UK). Data on SCC, fat percentage, protein percentage, and daily milk yield (DMY) were taken from these records and used in the analyses reported here. The DIM were calculated as the time between calving and milk sampling. The initial study population included all cows that were between DIM 40 and 200 at the time of the first sample collection. This also ensured that all cows in the study would still be milking at the time of the last sample. The sample population was determined by the first 12 viable cows to pass through the parlor at the time of the first sample collection. Following the preparation of the teat for milking, a 10-mL milk sample was collected from each of the 12 cows. Each sample contained milk from all 4 teats. Samples were taken monthly and were frozen before transport to the laboratory. Preliminary analyses (not shown) indicated that microparticle density was not altered by the freezing process compared with fresh milk taken from the same sample. 


\section{Sample Processing}

Polystyrene latex beads $(1.1 \mu \mathrm{m})$ from Sigma (Poole, UK), enumeration beads from Bangs Laboratories Inc. (Stratech Scientific Ltd., Luton UK), MC540 from Sigma, and phosphatidylethanolamine-cyanine dye (PE-Cy-7) conjugated annexin $\mathrm{V}$ and annexin $\mathrm{V}$ binding buffer from eBioscience (Cambridge, UK) were all used in this study. Prior to processing, milk was thawed in a water bath at $37^{\circ} \mathrm{C}$ until fully liquid and then placed on ice. From each sample, a whole-milk (WM) sample and a spun-milk (SM) sample were analyzed. Whole-milk samples were simply taken from $1 \mathrm{~mL}$ of the original milk sample. Spun milk samples were produced by placing $1 \mathrm{~mL}$ of WM into an Eppendorf tube and centrifuging at $2,400 \times g$ for $10 \mathrm{~min}$ at $4^{\circ} \mathrm{C}$ before transferring the supernatant to a clean Eppendorf tube, taking care to avoid the cream portion on the surface of the spun sample. Each original sample had 4 flow cytometric tests run: WM control sample, WM labeled sample, SM control sample, and SM labeled sample.

Labeled samples consisted of $10 \mu \mathrm{L}$ of WM or SM, 40 $\mu \mathrm{L}$ of $1 \times$ annexin $\mathrm{V}$ binding buffer and $2 \mu \mathrm{L}$ of annexin V. Samples were incubated on ice for 15 min before adding $450 \mu \mathrm{L}$ of MC540 diluted in $1 \times$ annexin V binding buffer. This was prepared by adding $10 \mu \mathrm{L}$ of $30 \mathrm{mM}$ MC540 to $10 \mathrm{~mL}$ of $1 \times$ annexin $\mathrm{V}$ binding buffer and filtering with a $0.22-\mu \mathrm{m}$ syringe filter. Following this, 1 $\mu \mathrm{L}$ of $1.1-\mu \mathrm{m}$ latex sizing beads (diluted 1:1,000 from manufacturer's stock in $1 \times$ annexin V buffer) and 10 $\mu \mathrm{L}$ of enumeration beads were added. Sizing beads and enumeration beads were vortexed before being added to the sample, and all sample tubes were vortexed for $5 \mathrm{~s}$ before being placed in the cytometer.

Control Samples. Control samples consisted of 10 $\mu \mathrm{L}$ of $\mathrm{WM}$ or SM and $490 \mu \mathrm{L}$ of $1 \times$ annexin $\mathrm{V}$ binding buffer, prepared by diluting appropriate volumes of $10 \times$ annexin $\mathrm{V}$ binding buffer in distilled water and filtering using a $20-\mathrm{mL}$ syringe and $0.2-\mu \mathrm{m}$ syringe filter.

Flow Cytometric Analysis. Flow cytometric analysis of microparticles in the milk samples was carried out using a Canto II cytometer (BD Biosciences, Oxford, UK) alongside Diva software (version 6.1; BD Biosciences). The machine was calibrated daily using Cell Tracker Beads (BD Biosciences). Before each test session, the following controls were run to ensure that microparticle populations were appropriately gated (Supplementary Figure S1; http://dx.doi.org/10.3168/jds.2014-8036): $500 \mu \mathrm{L}$ of $1 \times$ annexin $\mathrm{V}$ binding buffer, $1-\mu \mathrm{L}$ sizing beads in $499 \mu \mathrm{L}$ of $1 \times$ annexin $\mathrm{V}$ binding buffer (sizing bead gate), and $10-\mu \mathrm{L}$ enumeration beads in $490 \mu \mathrm{L}$ of $1 \times$ annexin $\mathrm{V}$ binding buffer (enumeration bead gate).

Forward-scatter voltage determines the size of particle that can be detected in the flow cytometer, whereas side-scatter voltage determines how granular a particle is. Both parameters were set to ensure that the microparticle population $(<1 \mu \mathrm{m}$ in size) could be detected in each sample (Supplementary Figure S1, microparticle gate; http://dx.doi.org/10.3168/jds.20148036). Macey et al. (2011) showed that the limit of detection for this instrument was below $0.1 \mu \mathrm{m}$. Sample acquisition was for $2 \mathrm{~min}$ at a low flow rate and set to record the highest number of events possible. The control milk samples were always analyzed immediately before their respective labeled samples to allow assessment of background noise and appropriate alteration of voltage gates (Orozco and Lewis, 2010). Voltage gates were set so that in the unlabeled control samples approximately $2 \%$ of events recorded fell within the areas of interest. The $2 \%$ gating of the negative control was to establish the level of background noise, or autofluorescence. It was important to set the voltages such that the negative control had a median fluorescence of approximately 102 to 103 (arbitrary scale) to ensure that all events were recorded during acquisition and minimize noise. Analysis of the labeled samples clearly demonstrated any events that fell into the microparticle gate and were labeled with annexin V, MC540, or both (double positive; Supplementary Figure S2; http:// dx.doi.org/10.3168/jds.2014-8036).

For the labeled samples, the number of microparticles per microliter (density) was calculated using Equation 1 with a dilution factor of 50 :

Microparticle density $=$

$\underline{20 \times \text { number of events counted } \times \text { dilution factor of sample }}$ number of enumeration beads counted

The population/events of interest were the total number of microparticles in WM or SM and those particles that were positive for annexin V, positive for MC540, or positive for both annexin V and MC540. Three samples were excluded from the analysis due to problems with the enumeration beads.

\section{Data Analysis}

The data collected from the 12 cows on 5 different monthly recording days is summarized in Table 1 . The microparticle data and SCC were heavily positively skewed and so were logarithmically transformed for all analyses. Pearson correlation coefficients were calculated between the 5 production traits DIM, SCC, fat percentage, protein percentage, and DMY and the 8 microparticle traits (Table 2), with their standard errors calculated as described by Gilmour et al. (2009; page 208). The general linear model (Equation 2) was 
Table 1. Summary of the data collected from 12 cows on 5 monthly recording days, showing mean, SD, and skewness before and after logarithmic transformation $(\mathrm{n}=57)$

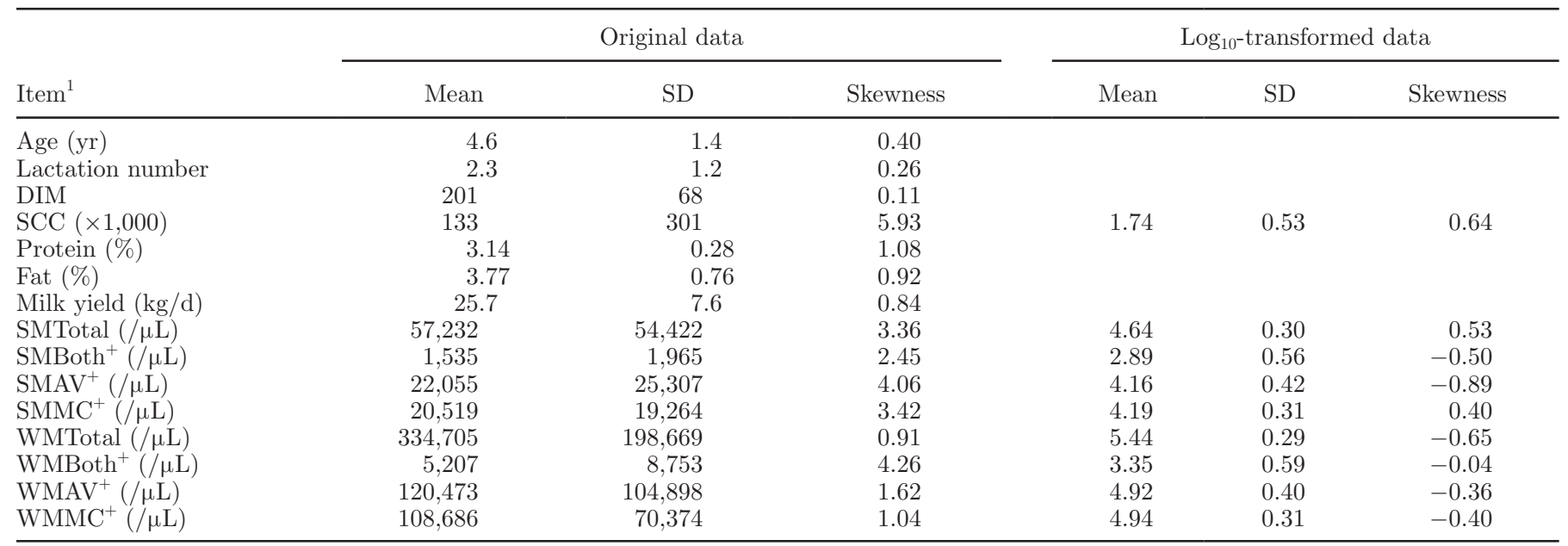

${ }^{1} \mathrm{SM}$ and $\mathrm{WM}=$ spun- and whole-milk samples, respectively; $\mathrm{AV}^{+}=$annexin V-positive microparticles; $\mathrm{MC}^{+}=$merocyanine $540(\mathrm{MC} 540)-$ positive microparticles; Both $^{+}=$microparticles positive for both annexin V and MC540; Total = all microparticles.

fitted to the 8 microparticle densities and daily milk yield to investigate the change in these traits over the period of lactation recorded and ASReml (Gilmour et al., 2009) was used for these analyses:

$$
\mathrm{Y}_{\mathrm{ij}}=\operatorname{cow}_{\mathrm{i}}+\mathrm{b}_{\mathrm{i}}\left(\mathrm{DIM}_{\mathrm{ij}}\right)+\mathrm{e}_{\mathrm{ij}}
$$

where $\mathrm{Y}_{\mathrm{ij}}$ was one of the 8 microparticle densities, or daily milk yield, for the ith cow and the jth time of milk collection; $b_{i}$ were the within-cow regression coefficients; and $\mathrm{e}_{\mathrm{ij}}$ was the residual term. The parameters of the 12 within-cow regressions were recovered from the analyses and used in a series of Pearson correlation coefficients, as described above. Further analyses were carried out fitting Equation 2 to the microparticle data but using SCC, fat percentage, and protein percentage as covariates.

\section{Results and Discussion}

The 12 cows in this trial averaged 4.6 yr of age, with a mean lactation number of 2.3 . They yielded $25.7 \mathrm{~kg}$ of milk/d over the 5 monthly milk collection days. Days in milk ranged from 47 to 323 , with a mean of $201 \pm$ $68 \mathrm{~d}$. The various microparticle populations measured are summarized in Table 1. Whole-milk microparticle densities were always higher than the equivalent densities from SM. The densities of annexin V-positive and

Table 2. Correlations between production traits and microparticle density traits $(\mathrm{n}=57)^{1,2}$

\begin{tabular}{|c|c|c|c|c|c|}
\hline Item & DIM & SCC & $\begin{array}{c}\text { Protein } \\
\text { percentage }\end{array}$ & $\begin{array}{c}\text { Fat } \\
\text { percentage }\end{array}$ & $\mathrm{DMY}^{3}$ \\
\hline $\mathrm{SCC}$ & 0.07 & & & & \\
\hline Protein percentage & 0.22 & 0.08 & & & \\
\hline Fat percentage & 0.16 & 0.02 & 0.03 & & \\
\hline DMY & -0.67 & 0.03 & -0.44 & -0.21 & \\
\hline SMTotal & 0.18 & 0.07 & -0.01 & -0.10 & -0.10 \\
\hline SMBoth $^{+}$ & 0.31 & -0.13 & -0.02 & 0.02 & -0.15 \\
\hline $\mathrm{SMAV}^{+}$ & 0.28 & -0.02 & -0.03 & -0.09 & -0.08 \\
\hline $\mathrm{SMMC}^{+}$ & 0.32 & 0.00 & -0.08 & -0.09 & -0.21 \\
\hline WMTotal & 0.57 & 0.11 & 0.08 & -0.06 & -0.42 \\
\hline WMBoth $^{+}$ & 0.46 & -0.08 & 0.00 & -0.06 & -0.33 \\
\hline WMAV $^{+}$ & 0.54 & 0.00 & 0.08 & -0.11 & -0.42 \\
\hline $\mathrm{WMMC}^{+}$ & 0.64 & 0.11 & 0.05 & -0.03 & -0.44 \\
\hline
\end{tabular}

${ }^{1} \mathrm{SM}$ and $\mathrm{WM}=$ spun- and whole-milk samples, respectively; $\mathrm{AV}^{+}=$annexin $\mathrm{V}$-positive microparticles; $\mathrm{MC}^{+}$ $=$ merocyanine 540 (MC540)-positive microparticles; Both $^{+}=$microparticles positive for both annexin $\mathrm{V}$ and MC540; Total $=$ all microparticles.

${ }^{2}$ Approximate SE of correlations: correlations of 0 to 0.4 had SE of approximately $0.12,0.5$ to 0.7 had SE of approximately 0.08 , and $>0.7$ had SE of approximately 0.05 . Correlations $>2 \mathrm{SE}$ are shown in bold. All microparticle traits and SCC were logarithmically transformed.

${ }^{3} \mathrm{DMY}=$ daily milk yield. 
MC540-positive particles were similar within each type of milk (WM and SM) and were much greater than the densities of particles positive for both reagents. Logarithmic transformation of these data resulted in a more normally distributed set of microparticle data, with skewness being reduced from $>1$ in most cases to between 0.53 and -0.89 . The SM densities were not used in the subsequent analyses due to their low correlations with most other traits and the lack of any relationship found with both DIM and DMY (not shown).

Days in milk, an indicator of the period of lactation when the milk samples were collected, was highly negatively correlated with DMY, as expected at this stage of lactation (Table 2). It was also significantly positively correlated with all 8 microparticle density measurements, implying that as lactation progressed, the density of microparticles in the milk also increased. This was further observed in the within-cow regression analysis, where all $4 \mathrm{WM}$ analyses showed a significant increase of microparticle density with increasing DIM (Table 3). One exception to this was total number of microparticles in WM, which only achieved a probability of 0.051. Somatic cell count, fat percentage, and protein percentage showed no correlation or relationship with any microparticle trait but DMY was negatively correlated with the $4 \mathrm{WM}$ traits. This implies that higher yields are associated with lower levels of microparticle density, and further general linear model analyses (not shown) also found this relationship within cow.

Persistency of milk yield is commonly used to describe the decrease in DMY after peak yield has been passed. In these analyses, a cow's persistency may be estimated as the slope of the line relating milk yield to DIM, within each cow. Table 3 shows the mean persistency in this sample of 12 cows to be $-0.097 \pm 0.010$ $\mathrm{kg} / \mathrm{d}$. Thus, on average, milk yield decreased by 97 $\mathrm{g} / \mathrm{d}$ in this trial. The correlations between DMY level, persistency, and characteristics of the $4 \mathrm{WM}$ densities are shown in Table 4. Persistency was significantly negatively correlated with all 4 microparticle density slopes, suggesting that the rate of decline in milk yield as lactation progressed was related to the rate of increase in microparticle density over the same period. The level of WM microparticle density per animal was also positively related to the persistency of milk yield for 2 of the 4 microparticle types (total and annexin $\mathrm{V}$ positive), such that higher microparticle densities per cow were associated with more persistent animals.

The relationship between the various microparticle densities was of interest. Within the type of milk analyzed, strong relationships existed between all 4 measures of microparticle density, with those between WM densities higher than the SM measures (Supplementary Table S1; http://dx.doi.org/10.3168/jds.2014-8036). The level of microparticle density, and its change during late lactation, is summarized in Table 4 for the WM samples. The correlation between the level and slope was strongly negative for all 4 types of microparticle. This implies that cows with higher density levels of a particle type also had slower rate of microparticle density increase as lactation progressed. Also cows tended to have similar rates of change in all 4 microparticle types, as shown by the high, positive correlations between the slopes in Table 4 (0.37 to 0.85).

In conclusion, we have shown that the extraction of microparticles from milk is a viable method. The limited data set used to demonstrate this method has, nevertheless, shown that this technique appears to bear out the hypothesis that an increase in microparticle density is associated with a decline in milk yield. As apoptosis of mammary secretory cells has been identified as a major cause of milk yield decline in late lactation, and microparticles are produced as a result of apoptosis, then this method might be a viable and noninvasive way of monitoring apoptosis in dairy animals. This analysis included cows that were already pregnant and, therefore, some microparticles could be due to proliferation of mammary cells. Further work is required to identify markers of cellular activation versus apoptosis, which may be related to internal cargo (e.g., microRNA and mRNA) or to cell surface markers that could be detected using suitable fluorochrome-conjugated anti-

Table 3. Analysis of variance summary from fitting the effects of each cow $(\mathrm{n}=12)$ and DIM $(\mathrm{n}=5)$ within cow as a linear function ${ }^{1,2}$

\begin{tabular}{lccccc}
\hline Item & $\begin{array}{c}\mathrm{DMY} \\
(\mathrm{kg} / \mathrm{d})\end{array}$ & $\begin{array}{c}\text { WMTotal } \\
(\mathrm{no} / \mu \mathrm{L})\end{array}$ & $\begin{array}{c}\text { WMBoth } \\
(\mathrm{no} / \mu \mathrm{L})\end{array}$ & $\begin{array}{c}\mathrm{WMAV}^{+} \\
(\mathrm{no} / \mu \mathrm{L})\end{array}$ & $\begin{array}{c}\mathrm{WMMC}^{+} \\
(\mathrm{no} / \mu \mathrm{L})\end{array}$ \\
\hline Cow & $* * *$ & $* * *$ & $* * *$ & $* *$ \\
DIM within cow & $* * *$ & 0.051 & $*$ & $* *$ & $* *$ \\
Residual & 5.59 & 0.038 & 0.249 & 0.070 & 0.037 \\
Mean cow intercept & $44.9 \pm 2.90$ & $4.9 \pm 0.080$ & $2.7 \pm 0.46$ & $4.2 \pm 0.027$ & $4.3 \pm 0.11$ \\
Mean slope $(/ \mathrm{d}) \pm \mathrm{SE}$ & $-0.097 \pm 0.010$ & $0.003 \pm 0.0004$ & $0.004 \pm 0.0024$ & $0.004 \pm 0.0014$ & $0.003 \pm 0.0005$ \\
\hline
\end{tabular}

${ }^{1} \mathrm{WM}=$ whole-milk samples; $\mathrm{AV}^{+}=$annexin V-positive microparticles; $\mathrm{MC}^{+}=$merocyanine $540(\mathrm{MC} 540)$-positive microparticles; Both ${ }^{+}=$ microparticles positive for both annexin V and MC540; Total = all microparticles.

${ }^{2}$ All microparticle traits were logarithmically transformed.

${ }^{3}$ Daily milk yield.

${ }^{* * *} P<0.001 ;{ }^{* *} P<0.01 ;{ }^{*} P<0.05$. 
Table 4. Correlations between daily milk yield (DMY), persistency, and the regression slope, and level for the 4 microparticle densities for each cow $(\mathrm{n}=12)^{1,2,3,4}$

\begin{tabular}{|c|c|c|c|c|c|c|c|c|c|}
\hline Item & DMY a & Persistency & WMTotal a & WMTotal b & $\mathrm{WMBoth}^{+} \mathrm{a}$ & $\mathrm{WMBoth}^{+} \mathrm{b}$ & $\mathrm{WMAV}^{+} \mathrm{a}$ & $\mathrm{WMAV}^{+} \mathrm{b}$ & $\mathrm{WMMC}^{+} \mathrm{a}$ \\
\hline WMTotal a & -0.35 & 0.63 & & & & & & & \\
\hline WMBoth $^{+} \mathrm{b}$ & 0.31 & -0.32 & -0.46 & 0.37 & -0.98 & & & & \\
\hline $\mathrm{WMAV}^{+} \mathrm{a}$ & -0.46 & 0.57 & 0.71 & -0.60 & 0.81 & -0.81 & & & \\
\hline $\mathrm{WMAV}^{+} \mathrm{b}$ & 0.38 & -0.50 & -0.64 & 0.69 & -0.81 & 0.85 & -0.95 & & \\
\hline
\end{tabular}

${ }^{1} \mathrm{WM}=$ whole-milk samples; $\mathrm{AV}^{+}=$annexin V-positive microparticles; $\mathrm{MC}^{+}=$merocyanine $540(\mathrm{MC} 540)$-positive microparticles; Both ${ }^{+}=$ microparticles positive for both annexin V and MC540; Total = all microparticles.

${ }^{2}$ Regression parameters: $\mathrm{a}=$ intercept (shown as cow in Equation 2 in the text) and $\mathrm{b}=$ slope.

${ }^{3}$ Approximate SE of correlations: correlations of 0 to 0.4 had SE of approximately $0.27,0.5$ to 0.7 had SE of approximately 0.19 , and $>0.7$ had SE of approximately 0.11 . Correlations $>2 \mathrm{SE}$ are shown in bold.

${ }^{4}$ All microparticle traits were logarithmically transformed.

bodies. Other work could include an investigation of different cell types in milk, as antibodies to PMNL, monocyte, and T-cell-specific markers are commercially available for bovines. In addition, several other issues need to be explored in relation to this method. A study of the change in microparticle density throughout the milking process would help inform future sampling strategies. A complete characterization of microparticle production throughout the whole of lactation would provide useful information on the timing of processes taking place as lactation progresses. Technical issues with the method relating to the effect of fat globules on the results should be explored, and a comparison between pregnant and nonpregnant lactating cows would help highlight the effects of pregnancy on microparticle density.

\section{ACKNOWLEDGMENTS}

We acknowledge the Wellcome Trust (London, UK) for the vacation scholarship used to fund L. Jerram.

\section{REFERENCES}

Albarrán-Portillo, B., and G. E. Pollott. 2008. Genetic parameters derived from using a biological model of lactation on records of commercial dairy cows. J. Dairy Sci. 91:3639-3648.

Azevedo, L. C. P. 2012. Microparticles and exosomes: Are they part of important pathways in sepsis pathophysiology? Pages $155-166$ in Severe Sepsis and Septic Shock-Understanding a Serious Killer. D. R. Fernandez, ed. InTech, Rijeka, Croatia.

Burnett, L. A., M. M. Light, P. Mehrotra, and R. A. Nowak. 2012. Stimulation of GPR30 increases release of EMMPRIN-containing microvesicles in human uterine epithelial cells. J. Clin. Endocrinol. Metab. 97:4613-4622.

Capuco, A. V., S. E. Ellis, S. A. Hale, E. Long, R. A. Erdman, X. Zhao, and M. J. Paape. 2003. Lactation persistency: Insights from mammary cell proliferation studies. J. Anim. Sci. 81:18-31.

Capuco, A. V., D. L. Wood, R. Baldwin, K. Mcleod, and M. J. Paape. 2001. Mammary cell number, proliferation, and apoptosis during a bovine lactation: Relation to milk production and effect of bST. J. Dairy Sci. 84:2177-2187.
Diamant, M., M. E. Tushuizen, A. Sturk, and R. Nieuwland. 2004. Cellular microparticles: New players in the field of vascular disease? Eur. J. Clin. Invest. 34:392-401.

Gilmour, A. R., B. J. Gogel, B. R. Cullis, and R. Thompson. 2009 ASReml User Guide Release 3.0. VSN International Ltd., Hemel Hempstead, UK.

Knight, C. H., and M. Peaker. 1984. Mammary development and regression during lactation in goats in relation to milk secretion. Q. J. Exp. Physiol. 69:331-338.

Knight, C. H., M. Peaker, and C. J. Wilde. 1998. Local control of mammary development and function. Rev. Reprod. 3:104-112.

Knight, C. H., and C. J. Wilde. 1993. Mammary cell changes during pregnancy and lactation. Livest. Prod. Sci. 35:3-19.

Macey, M. G., N. Enniks, and S. Bevan. 2011. Flow cytometric analysis of microparticle phenotype and their role in thrombin generation. Cytometry B Clin. Cytom. 80:57-63.

McCarthy, D. A., M. G. Macey, and P. D. Allen. 2008. A simple, novel, procedure for monitoring membrane scrambling and permeability in microparticles, platelets, and leukocytes in whole blood samples. Exp. Hematol. 36:909-921.

Nantakomol, D., P. Chimma, N. P. Day, A. M. Dondorp, V. Combes, S. Krudsood, S. Looareesuwan, N. J. White, K. Pattanapanyasat, and K. Chotivanich. 2008. Quantitation of cell-derived microparticles in plasma using flow rate based calibration. Southeast Asian J. Trop. Med. Public Health 39:146-153.

Orozco, A. F., and D. E. Lewis. 2010. Flow cytometric analysis of circulating microparticles in plasma. Cytometry A 77:502-514.

Pollott, G. E. 2000. A biological approach to lactation curve analysis for milk yield. J. Dairy Sci. 83:2448-2458.

Pollott, G. E. 2004. Deconstructing milk yield and composition during lactation using biologically based lactation models. J. Dairy Sci. $87: 2375-2387$

Quarrie, L. H., C. V. P. Addey, and C. J. Wilde. 1995. Apoptosis in lactating and involuting mouse mammary tissue demonstrated by nick-end DNA labelling. Cell Tissue Res. 281:413-419.

Stefanon, B., M. Colitti, G. Gabai, C. H. Knight, and C. J. Wilde. 2002. Mammary apoptosis and lactation persistency in dairy animals. J. Dairy Res. 69:37-52.

Théry, C., M. Ostrowski, and E. Segura. 2009. Membrane vesicles as conveyors of immune responses. Nat. Rev. Immunol. 9:581-593.

van der Pol, E., A. N. Böing, P. Harrison, A. Sturk, and R. Nieuwland. 2012. Classification, functions, and clinical relevance of extracellular vesicles. Pharmacol. Rev. 64:676-705.

Wilde, C. J., L. H. Quarrie, E. Tonner, D. J. Flint, and M. Peaker. 1997. Mammary apoptosis. Livest. Prod. Sci. 50:29-37.

Yart, L., F. Dessauge, L. Finot, S. Barbey, P. G. Marnet, and V. Lollivier. 2012. Ovariectomy improves lactation persistence in dairy cows. J. Dairy Sci. 95:3794-3802. 